Supporting Information

\title{
Styrenic BAB Triblock Copolymers Functionalized with Lithium $(N$ - Tetrafluorophenyl)trifluoromethanesulfonamide as Solid Single-ion Conducting Electrolytes
}

\author{
Zhecheng Shao, Hannes Nederstedt and Patric Jannasch* \\ Polymer \& Materials Chemistry, Department of Chemistry, Lund University, \\ P.O. Box 124, SE-221 00, Lund, Sweden. \\ *patric.jannasch@chem.lu.se
}




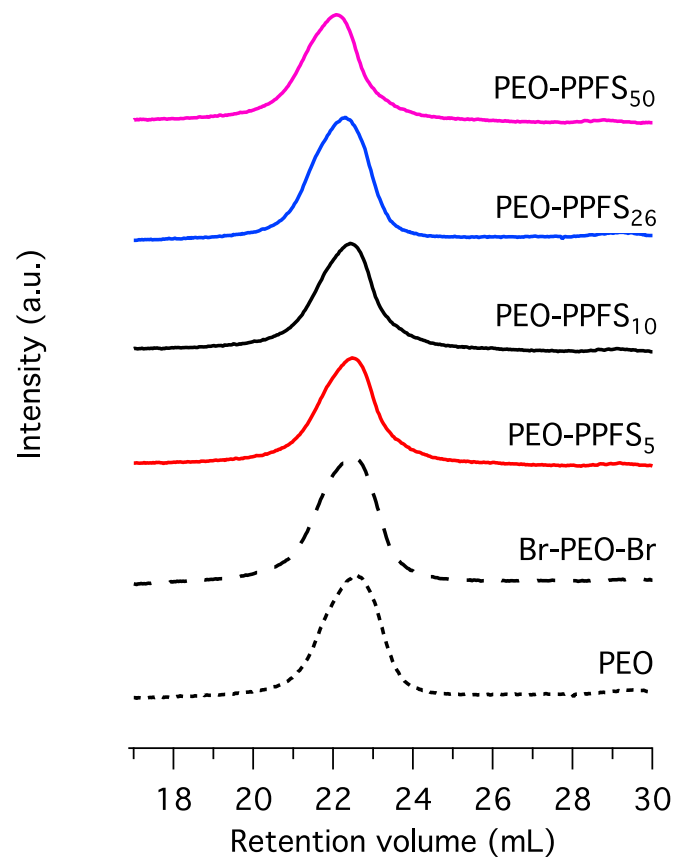

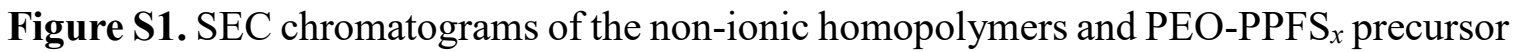
block copolymers.
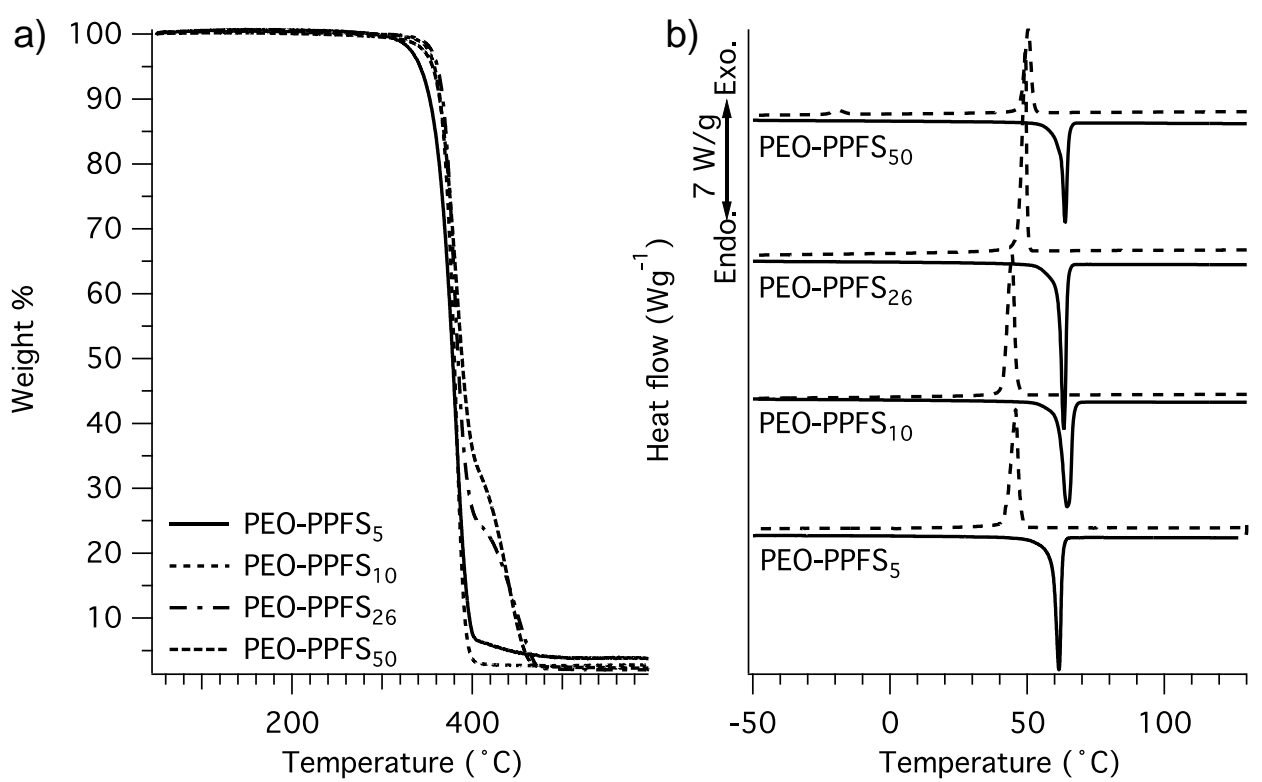

Figure S2. TGA (a) and DSC (b) traces of the PEO-PPFS $x$ precursor block copolymers. 


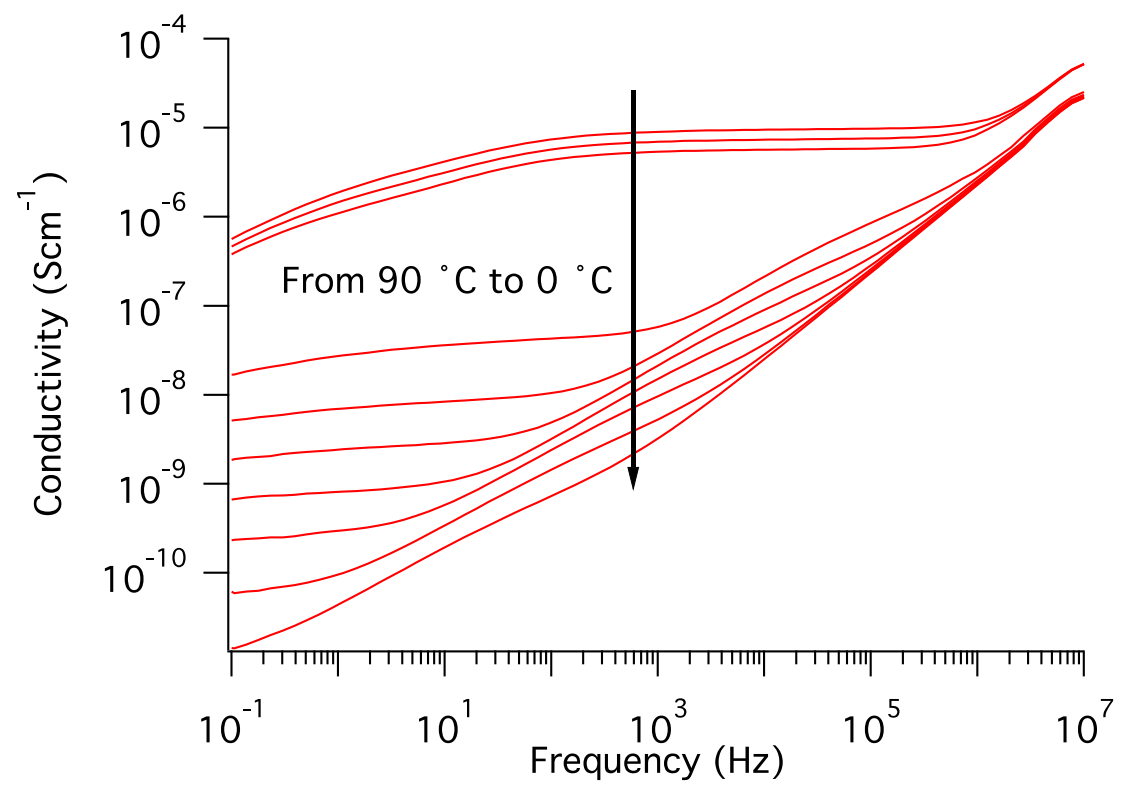

Figure S3. Conductivity versus frequency for sample PEO-TfnPPFSLi 16 measured by impedance spectroscopy from 90 to $0{ }^{\circ} \mathrm{C}$ in steps of $10{ }^{\circ} \mathrm{C}$.

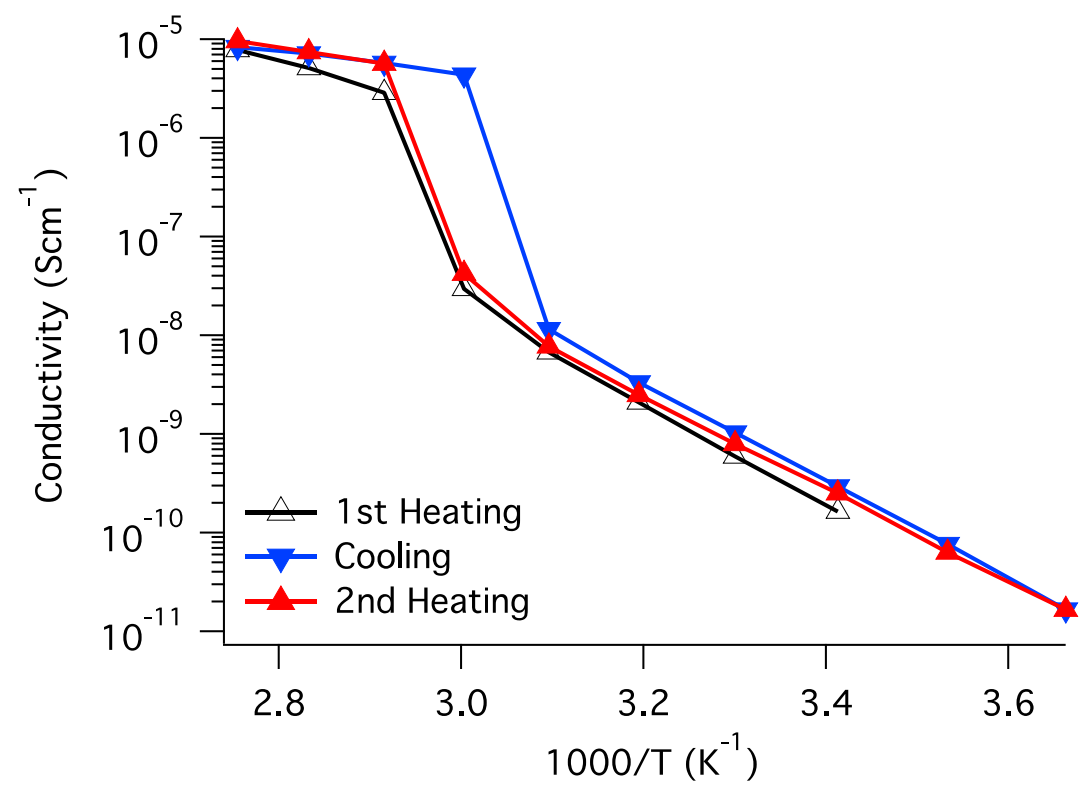

Figure S4. Conductivity data measured during heating-cooling-heating scans of PEOTfnPPFSLi 16 in the temperature range $0-90{ }^{\circ} \mathrm{C}$ in steps of $10^{\circ} \mathrm{C}$. 